DOI: 10.17707/AgricultForest.61.1.33

\author{
Rosanna QUAGLIARIELLO, Atef HAMDY, \\ Giuliana TRISORIO LIUZZI and Chiara CIANNAMEA ${ }^{I}$
}

\title{
ACHIEVING GENDER EQUALITY AND SUSTAINABLE RURAL DEVELOPMENT IN THE MEDITERRANEAN: INSTITUTIONAL OBSTACLES AND POSSIBLE SOLUTIONS
}

\begin{abstract}
SUMMARY
In almost all developing countries it is well recognised that there are certain institutional obstacles which seriously and negatively affect any progress towards achieving gender equality. Deep analysis of gender mainstreaming in most of those countries indicate clearly that institutional obstacles are numerous and are mainly attributed to the presence of cultural, socio, economic and empowerment reasons. Indeed for many of developing countries despite the political and commitments at various levels of interventions, gender remains as everyone's business and no one's business at the same time. Thus when it comes to implementation, it ends up with notable failure. This explains clearly why policy commitment to gender mainstreaming evaporates when it comes to the actual planning and implementation process. This is quite happening due not only to lack of understanding capacity on gender mainstreaming and how to apply it in a political sense but also due the fact that there is shortage of reliable and relevant sex disaggregated data as well as the absence of gender sensitivity / capacity among managers and technical staff involved in monitoring and evaluation (MGE) process.

Identifying the obstacles and the reasons behind is an essential step, but, the important step that should be followed is how these obstacles could be removed. Experiences gained and learned lessons highlight that possible solutions could be found through having an appropriate vision approach and legislation and a clear referral frame work to apply. Equally there is a need for appropriate institutional arrangements and reporting mechanisms, training and development of capacity and expertise in gender mainstreaming, and to ensure women's empowerment towards gender equality.

Keywords: Gender mainstreaming, sustainable rural development, gender equity, women empowerment, gender politics

\footnotetext{
${ }^{1}$ Rosanna QUAGLIARIELLO, (corresponding author: quagliariello@iamb.it), Gender division, CIHEAM/Mediterranean Agronomic Institute, Bari, ITALY, Atef HAMDY, Emeritus Professor, Water Resources Management, CIHEAM/Mediterranean Agronomic Institute, Bari, ITALY, Giuliana TRISORIO LIUZZI, University of Bari, Department of 'Scienze Agro-Ambientali e Territoriali' - DISAAT, ITALY and Chiara CIANNAMEA, Gender division,
} CIHEAM/Mediterranean Agronomic Institute, Bari, ITALY.
\end{abstract}

Paper presented at the $5^{\text {th }}$ International Scientific Agricultural Symposium "AGROSYM 2014".

Notes: The authors declare that they have no conflicts of interest. Authorship Form signed online. 


\section{INTRODUCTION}

Gender inequality is present in many assets, inputs and services: e.g. access to or control over land, financial services, productive resources and extension or marketing services. Similar gaps exist in access to fertilizers, mechanical equipment, new technologies, extension services and credits (UNDP, 2012). Moreover, women are often underrepresented in rural organizations and institutions and generally poorly informed regarding their rights. This prevents them from having an equal say in decision making process, and reduce their ability to participate in collective activities as members of agricultural cooperatives or water user associations (Hamdy et al., 2010).

Indeed gender inequalities exist all along the food production chain, beginning with asymmetries in ownership of access to and control of livelihood assets such as land, water energy, credits, knowledge and labor.

If women had the same access to productive resources as men, they could increase yields and their farms by $20-30 \%$. This in turn could raise total agricultural output in developing countries by up to $4 \%$ potentially reducing the number of hunger people by 100-1500 million (FAO, 2002).

Regarding the gender approach to the water sector the cost-effectiveness have been amply demonstrated.

Furthermore, the need for mainstreaming gender in Integrated Resources Management (IWRM) has been validated from around the world. This has been highlighted and stressed by several issued statements (Inter-Ministerial Conference on Freshwater, Bonn, Germany 2001; The World Summit of Sustainable Development (WSSD), Johannesburg, 2002; The 2nd World Water Forum, The Hague, 2000) and in the 3rd World Water Forum, Kyoto, Japan 2003).

At the WSSD, world leaders committed themselves to a gender approach with international water management and practice. In Bonn government representatives responsible for water resources stated in their final declaration: "Water resources management should be based on participatory approach. Both men and women should be involved and have an equal voice in managing the sustainable use of water resources and sharing of benefits. The role of women in water related areas needs to be strengthened and their participation broadened.

Such International events, beside several Mediterranean and national conferences dealing the mainstreaming gender in the water sector, equally the ample programme realized by Ciheam-Bari Institute for more than 15 tears, all emphasized clearly the following facts:

-by the adoption of a gender approach, both efficiency and equity goals could be promoted;

-the human and social dimensions of water management are to be the cornerstone of new initiatives;

-all too often, gender policies strategies or actions plans are included with no clearly defined activities and targets, as well as the allocation of stuffing and financial resources. 
However, around these facts, several questions were raised including:

-How is such policy to be implemented?

-What follows at the operational level?

-What are "gender sensitive infrastructure and services?

-How can we strengthen the role of women and how to ensure they have an equal voice and choice? And, as a priority question,

-What are the basic conceptual underpinning of the gender approach?

In this manuscript, such surrounding questions beside others will be discussed in relation to sustainable rural development in the Mediterranean and the needed institutional mechanisms.

\section{Gender equity}

\section{RESULTS AND DISCUSSION}

While real advances in gender equality have occurred over the past 25 years, there remains and immense gap between the promises of equality and everyday reality for women in many parts of the world.

Greater gender equality can increase productivity, improve outcomes for children, make institutions more representatives, and improve development prospects for all. The fruits of growth and globalization should be shared equally between men and women for equitable development giving women equal opportunities to be socially and politically active, positively influences laws, policies, and makes institutions more representative of a range of voices.

Gender inequalities result in less food been grown, less income being earned and higher levels of poverty and food insecurity.

Politicians have taken note of these facts and figures. Gender equality is clearly recognized as a human right on an international level. Over the past several years, UN member states have entered into a number of commitments. The Rome declaration of food security(FAO, 1996), resulting from the FAO World Food Summit in 1996, affirms the obligations to promote the equal rights and duties of men and women regarding food security. The Millennium DevelopmentGoals (UN, 2000) underline the fact that, without gender equality, it will be impossible to reduce by half the number of people who suffer from hunger by 2015. With its development policy Action plan on Gender 2009-2012, the German Federal Ministry for Economic Cooperation and Development (BMZ, 2013)has committed to strengthening the economic empowerment of women. Gender equity necessitates having an adequate policy and legal framework.

It's important to include the resource rights of women into the legislative framework. Effective mechanisms of control of power include regulatory guaranties.

For equal treatment of men and women, a non discriminatory procedural law as well as appropriate judicial and non judicial authorities for appeals. These mechanisms can give the necessary legal security to both, men and women, as well as strength peaceful processes of conflict arbitration. The international 
organizations and agencies can play an important role in completing and implementing these mechanisms and each of the priority areas as well as through better data, impact evaluation and learning (WorldBank, 2012a; b).

\section{Gender equity- Action areas}

In rural areas focused domestic public policies remain the key to bringing equality and ensuring that the potential of globalization for women is actually realized.

This question which is addressed where should countries focus and what should they do? Answering the question suggests that actions are needed in four priority areas (CIHEAM, 2005).

-Addressing human capital issue

-Closing earning and productivity gaps between women and men

-Giving women greater voice within households and societies, and

-Limiting the reputation of gender inequality across generations

\section{Hidden gender equality: problems}

Several problems do exist among them the following (Valian, 2002):

-Lack of knowledge about whether gender equality problems exist

-Lack of interest in gender equity on the part of administrators, division heads, chairs and others

-Institutional practices with inadvertent disproportional impact

-Lack of knowledge about how gender schemes work to advantage men and disadvantage women

- Lack of awareness of likelihood of overvaluing men and undervaluing women

-Belief that excellence is transparent and obvious

-Underexplored research and teaching concerning gender equity

-Gender disparities in knowledge of internal resources, access to internal research funds, access to technical and computer assistance, access to secretariat and research assistance centers for women and gender equality

While women represent a large portion of the Third World's labor force, they still remain disadvantaged in securing decent paid labor, socio-cultural attitudes, lack of a second legislative framework for gender equality, unfair labor distribution and inequality in the labor markets. These are all factors that contribute to gender inequality and all can be resolved with the implementation of successful gender mainstreaming (GEF, 2008).

Most countries and particularly the developing ones recognize that issues of gender equality are matters of cultural norms and constant challenges and barriers. They are showing up that gender mainstreaming can and will close the goal, playing a major role in adding value to overcome the challenges and barriers. Leadership and government commitment are major contributing factors to a successful mainstreaming (Meinzen-Dick et al., 2011). 
A constructive joint effort toward gender mainstreaming by men and women serves a common goal and along with a firm commitment from local and government and community, will be the key to reducing poverty in rural areas and contribute to (WorldBank, 2010):

-Economic development and growth-working side by side with mate counters parts for common goals to build a better community

-Building an effective governance with heavy involvement in local government and public policy decision making

Gender mainstreaming in local government will have a major effect in rural development. Women along the side men can jointly develop a strategic plan on community-based level to strengthen rural development planning with progressive women's participation in local government.

\section{Gender mainstreaming and rural development}

Gender mainstreaming has evolved since early 1990's and been growing gradually ever since mainly in developing/under developed countries. The most important and special concept of the process of gender mainstreaming is the fact that it contributes to equal opportunities, obligations and rights of both women and men. Indeed in a less complicated definition it means that gender equality becomes a full part of common policies.

In rural areas development gender mainstreaming encompasses all aspects of planning, implementing monitoring and social political or economic action to successfully mainstream gender in rural areas, internal local governments and the community should make a firm commitment to embrace the goals and have a clear understanding of the values of mainstreaming that contributes to economic and rural development.

On the local level, the organizational culture has to be transformed from gender bias to gender balanced by integrating women, appointing men in a key position in local government, policy analysis and decision making.

On the external level, appropriate steps should be taken to mainstream gender into development operations such as design, implementation and evaluation.

For most developing countries it is needed to establish a solid framework in rural areas having the following key dimension: political will, technical capacity, accountability and organizational culture.

The UN Millennium Project (2000) suggested that gender equality encompass three main dimension capabilities including basis human abilities in education health and nutrition, access to resources and opportunities (considering also access to economic assets such as land and infrastructures, resources such as income and employment, and political opportunities such as representation in political bodies and security including reduced vulnerability to violence and conflict). 


\section{Successful gender mainstreaming in rural development: attributed element Empowering women}

Women's empowerment is defined as women's ability to make strategic life choices where the ability had been previously denied them (Kabeer, 2003). Empowerment is articulated the midway in the change processes that benefit women at individual, household, community and broader level.

Gender equality and women's empowerment is the third of eight MDG. It is an intrinsic rather than an instrumental goal, explicitly valued as an and itself rather than an instrumental for achieving other goals. Three resources: education, employment and political participation are considered essential to the achievement of gender equality and women's empowerment. Each of these resources has the potential to bring about positive changes in women's lives, but in each case, it is the social relationships that govern access to the resources in question that will determine the extent to which this potential is realized (AFDB, 2008).

In rural areas when women are empowered and can claim their rights and access to land, leadership, opportunities and choices, economics grow, food security is enhanced and prospects are improved for current and future generations. Equally when women are empowered economically and socially, they become leaders and agents of change for economic growth, social progress and sustainable development in rural areas. Technically and politically, it is well recognized that empowerment of women in rural areas is a pre-requisite for global food security and sustainable development (IFAD, 2012).

Empowering women through education, employment opportunities and decision making in economical political affairs is the key ingredient to accelerating gender mainstreaming in rural development. Indeed empowerment is a key aspect towards achieving gender equity and reducing women vulnerability in rural areas. Women must have the skills and capacity to ensure that their needs are met. Therefore, it is recommended that a gender focused service delivery mechanism could be developed to be applied to rural development sustainability (Johnsson-Latham, 2007).

\section{Participation in politics and governance}

The goals of gender mainstreaming into politics and governance in all public administration levels in particular in rural areas are:

-To ensure balanced participation between men and women in national and/or rural governance, this includes removal of structural and systematic carriers to women's participation.

-To ensure that gender issues are integrated into decision making, implementation, monitoring and evaluation with local and national governance initiatives.

The most important component to succeeding in the political arena is a commitment by the local government to initiate, develop and implement a training and skill development strategy. Parallel to this, it is absolutely important 
to conduct research to analyze the problems, and the obstacles that hinder women full participation in rural and national political arenas in order to take the appropriated measurements needed to meet the existing challenges.

Education and training mainstreaming as a strategy to achieve gender equality acknowledges that women and men have different needs, situation and resources with respect to their participation in agriculture and rural development activities. Providing education and training in agriculture and farming which speed the process and can be instrumental in overcoming barriers with a lack of education and training in the agricultural sector, techniques and resources are still limited and not addressing the different problems and needs between women and men. Successful gender mainstreaming in rural development particularly in agriculture and farming is in need to a tailored and customized training program to meet the requirements of both women's and men's work (Hamdy et al., 2004).

Technical training had to follow lines and closely parallel women's existing roles and responsibilities. The same pattern should be followed with women vocational training.

\section{Access funding through Micro-Finance}

Microfinance had proven to be a constructive tool to provide the rural poor with seed money and access to small amounts of credits at reasonable interest rate to enable them to set up micro/small business in rural areas. Women will thus be able to invest in both farm and non-farm enterprises to create productive assets.

\section{obstacles \\ Mainstreaming gender in rural development Implementation}

At the institutional level there is a weak understanding of the principles of gender equity and benefits which can be achieved by gender mainstreaming in terms of achieving wider objectives such as sustainable development.

In addition to lack of understanding of the benefits and moral imperatives of a gender equity approach, there are two further obstacles to mainstreaming gender into rural development (Nilsson, 2013):

The first is the lack of disaggregated statistical and qualitative data. There are still few studies done to understand the tide relationship between gender mainstreaming and gender equity on rural development. This is further exacerbated by the lack of disaggregated statistical data at the national level. Without this basic understanding, it is impossible to design appropriate projects or to measure progress towards objectives.

Secondly, in many developing countries women's representation on decision making bodies, national or local, political or project is weak. Their lack of voice in these fora means that women's interests are not adequately taken into account when decisions are made.

Gender analysis in rural development programmes evidently show that there is adequate understanding of gender, poverty and vulnerability in relation to 
rural development but there had been insufficient focus on the incorporation of this analysis into the development programmes. The inclusion of gender in the policies and programmes documents but not in the implementation framework to rural development is a backward step (Kabeer, 1999).

In rural areas, the analysis of legal and policy framework give the evidence that there are several opportunities for strengthening the incorporation of gender issues into the development process.

\section{Gender equality: Institutional mechanisms}

The major goal of gender equality is to achieve equality between women and men in sustainable agricultural production and rural development for the elimination of hunger and poverty. To ensure that gender mainstreaming and women specific targeted intervention are implemented, there are important institutional mechanisms that should be included in the national and local rural development policies. These involve: the creation of an inter-departmental steering committee to guide and oversee over all progress; the development of a clear internal accountability structure; the development of staff capacity on gender equality; gender sensitive communications and partnership building; establishment of knowledge building system and gender sensitive monitoring and reporting evaluation and audit.

\section{Institutional obstacles}

For most developing countries there are institutional obstacles to attaining gender equality. Bari Institute experience and learned lessons provided by INGEDI and GEWAMED project showed that these obstacles could be characterized as:

Many government entities and agencies adopt gender mainstreaming policies, but in most cases they are in name only. This is mainly due to lack of understanding capacity on gender mainstreaming and how to apply it in a practical sense; Ministers and institutions may adopt gender mainstreaming policies, but often don't train staff to understand what this means in practice. As a result, managers do not know how to integrate gender as part of their projects;

There is a lack of reliable and relevant sex-disaggregated data for collective gender mainstreaming and monitoring and evaluation. In addition there is a lack of gender sensitivity/capacity among people who are in charge of mainstreaming and monitoring and evaluation. Policy commitments to gender mainstreaming are poorly considered in both actual planning and implementation processes.

Identifying the constraints is an important step, but, it is not sufficient, it is needed to find out what are the solutions in order for these obstacles to be removed. In other words what are the solutions?

\section{The solutions}

In order to achieve gender mainstreaming in an effective manner, specific prerequisites are needed including the followings: 
-A legally backed public entity to promote equality (national legislation and policies, international commitments

-Incentives to build ownership and increase efficiency and effectiveness

-Appropriate institutional arrangements and reporting mechanisms including collecting and making available sex-disaggregated data across all sectors

-Gender awareness and advocacy activities

-Legislation is enforced and mechanisms for rule of law and accountability are in place

-Training and development capacity and expertise gender mainstreaming

-Changing the partnership among government institutions, gender specific ministers, organizations and gender experts in order to promote gender mainstreaming in developing and influencing environment programme

-Legal institutions must be changed to create a level playing field for men and women and an environment in which women can realize their full potential

-The institutional/framework should be gender responsive. The existing cultural divide separating gender staff from technical staff and economic staff needs to be narrowed by increasing mutual understanding of the concepts, priorities, strategies and instruments developed by both groups

-Following a bottom up approach of involving communities in identifying the challenges they face and thereby enabling in building the programmes on existing mechanisms and initiatives which share gender equity objectives.

\section{CONCLUSIONS}

In summary there are still many opportunities to mainstreaming gender in the implementation of rural development policies and strategies which strengthen the ability of communities to adapt to running programmes. Moreover, if the capacity of existing local level institutions and service delivery mechanisms to address gender is strengthened, these mechanisms can be useful for achieving the goal of gender equality. Indeed with a little work gender equity can be addresses through these existing mechanisms, but what is lacking or what is still needed is the political will and commitment to ensure that this takes place.

In addition to a lack of understanding of the benefits and moral imperatives of gender equity approach, there are several obstacles to mainstreaming gender in rural development programmes and policies such as:

-The lack of disaggregated statistical and qualitative data. There still very few studies done to understand the differential impacts of rural development on women and men. This is further exacerbated by the lack of disaggregated statistical data at the national level without the basic understanding, it is impossible to design appropriate projects or to measure progress towards objectives

-Women's representation on decision making bodies, national or local political programmes or project is weak. The lack of voice of these forces means 
that women's interests are not adequately taken into account when decisions are made.

No blueprint exists for closing gender gap in rural development policies and strategies, but, some basic principles are universal: governments, the international community and civil society should work together to eliminate discrimination under the law, to promote equal access to resources and opportunities, to ensure that agricultural policies and programmes are gender aware and to make women's voices heard as equal partners for sustainable rural development which requires openness and transparency regarding gender disparities.

To conclude gender should be everyone's concern, but it needs people to push the envelope, and focal points who understand both what the concept of gender means and how to integrate it into programmes and policies. To achieve specific level there, it is needed an appropriate vision/approach and legislation and a clear referral framework to apply.

\section{REFERENCES}

AFDB (2008). Gender Equality and Women's Empowerment. An Updated Plan of Action (Ugpoa) 2009-2011, African Development Bank,

BMZ (2013). Gender and Rural Development Federal Ministry for Economic Cooperation and Development. Deutsche Gesellschaftfür Internationale Zusammenarbeit (GIZ) Gmbh, Stuttgart.

CIHEAM (2005). Gender Mainstreaming in the Water Sector: Theory, Practices, Monitoring and Evaluation. In: Hamdy, A. (eds). page (157).

FAO (1996). Rome Declaration on World Food Security and World Food Summit: Plan of Action., Food and Agriculture Organisation, Rome. Italy.

FAO (2002). Rural Women: Crucial Partners in the Fight against Hunger and Poverty. Food and Agriculture Organisation.

GEF (2008). Mainstreaming Gender in Gef.Global Environmental Facility.http://www.thegef.org/gef/gender Accessed on 15/05/2014.

Hamdy, A., Sagardoy, J.A., El Kady, M., Quagliariello, R., Bogliotti, C. (ed) (2004). Training of Trainers in Integration of Gender Dimension in Water Management in the Mediterranean Region. Ingedi Project, The Gender Dimension in Training at the Institute of Water Technology. Options Méditerranéennes:Série A. Séminaires Méditerranéens; n. 64, CIHEAM-IAM BARI, Cairo. Egypt.

Hamdy, A., TrisorioLiuzzi, G.,Rosanna, Q. (2010). Gender and Sustainable Rural Developement in Africa and Semi-Arid Regions of the Arab World. In: Abuzeid, A., Hamdy, A. (eds). Gender and Water Ressources Management and Development, page (215-231).

http://www.fao.org/worldfoodsummit/sideevents/papers/Y6832e.htm Accessed on $08 / 05 / 2014$

IFAD (2012). Gender Equality and Women's Empowerment: Policy, International Fund for Agricultural Development.

Inter-Ministerial Conference on Freshwater, Bonn, Germany (2001). Ministerial session of the International Conference on Freshwater. Bonn. 2001. Ministerial declaration. http://www.water-2001.de/outcome/ministerial-declaration.asp. Accessed on 23/06/2014. 
Johnsson-Latham, G. (2007). A Study on Gender Equality as a Prerequisite for Sustainable Development The Environment Advisory Council, Ministry of the Environment, Stockholm,

Kabeer, N. (1999). The Conditions and Consequences of Choice: Reflections on the Measurement of Womenís Empowerment. Discussion Paper No. 108, Unrisd United Nations Research Institute For Social Development, Geneva.

Kabeer, N. (2003). Gender Mainstreaming in Poverty Eradication and the Millennium Development Goals.A Handbook for Policy Makers and Other Stakeholders, Commonwealth Secretariat London.

Meinzen-Dick, R., Johnson, N., Quisumbing, A., Njuki, J., Behrman, J., Rubin, D., Peterman, A.,Waitanji, E. (2011). Gender, Assets, and Agricultural Development Programs: A Conceptual Framework. Capri Working Paper No. 99., International Food Policy Research Institute., Washington, D.C.

Nilsson, P. (2013). Gender and Development: The Challenge of Mainstream, Consilience:The Journal of Sustainable Development, 10. (1.), page (pp 125135).

The 2nd World Water Forum, The Hague (2000). Perspective The 2nd World Water Forum at The Hague, March 2000-Jon Lane Water Policy 2 (2000) 465-467. 2000 Published by Elsevier Science Ltd. All rights reserved.

The World Summit of Sustainable Development (WSSD), Johannesburg (2002). WORLD SUMMIT ON SUSTAINABLE DEVELOPMENT- 26 August - 4 September 2002. Johannesburg, South Africa http://www.un.org/jsummit/html/documents/summit_docs.html.

Third World Water Forum, Kyoto, Japan (2003). The 3rd World Water Forum: March 16-23, 2003. Kyoto, Shiga and Osaka, Japan http://www.iisd.ca/crs/3wwf/. Accessed on 23/06/2014

UN (2000). Millennium Development Goals. Millennium Declaration, Millennium Summit. General Assembly 55th Session. United Nations Development Programme. http://www.un.org/millennium/declaration/ares552e.htm Accessed on $12 / 04 / 2014$.

UNDP (2012). Africa Human Development Report 2012. Towards a Food Secure Future. United Nations Development Programme.

Valian, V. (2002). Analyzing and Correcting Hidden Gender Equity Problems. Department of Psychology, Hunter College and CUNY Graduate Center.Updated 20November2002.http://www.hunter.cuny.edu/genderequity/repository/files/equit y-materials/hidden.pdf Accessed on 18/05/2014.

WorldBank (2010).Gender and Environment Issues. Paper Draft., World Bank, Washington DC.

WorldBank (2012a). Data and Research_ Women and the 2012 World Development Repor.WorldBank.http://econ.worldbank.org/WBSITE/EXTERNAL/EXTDEC/0, ,contentMDK:23002997 pagePK:64165401 piPK:64165026 theSitePK:469372, 00.html Accessed on 11/04/2014.

WorldBank (2012b). World Development Report 2012, Gender Equality and Development.WorldBank.http://econ.worldbank.org/WBSITE/EXTERNAL/EXT DEC/EXTRESEARCH/EXTWDRS/EXTWDR2012/0,,contentMDK:23004468 pagePK:64167689 piPK:64167673 theSitePK:7778063,00.html Accessed on 23/06/2014. 